\title{
Kidney Health for Everyone Everywhere - From Prevention to Detection and Equitable Access to Care
}

\author{
Philip Kam-Tao Li ${ }^{a}$ Guillermo Garcia-Garcia ${ }^{b}$ Siu-Fai Lui ${ }^{c}$ \\ Sharon Andreolid ${ }^{d}$ Winston Wing-Shing Fung ${ }^{a}$ Anne Hradsky ${ }^{e}$ \\ Latha Kumaraswami ${ }^{f}$ Vassilios Liakopoulos $^{g}$ Ziyoda Rakhimova ${ }^{e}$

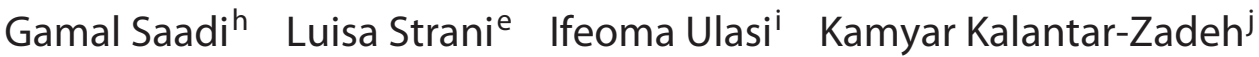 \\ for the World Kidney Day Steering Committee
}

\begin{abstract}
a Department of Medicine and Therapeutics, Carol and Richard Yu PD Research Centre, Prince of Wales Hospital, Chinese University of Hong Kong, Hong Kong, China; bephrology Service, Hospital Civil de Guadalajara Fray Antonio Alcalde, University of Guadalajara Health Sciences Center, Guadalajara, Mexico; 'Division of Health System, Policy and Management, Jockey Club School of Public Health and Primary Care, The Chinese University of Hong Kong, Hong Kong, China; d James Whitcomb Riley Hospital for Children, Indiana University School of Medicine, Indianapolis, IN, USA; 'World Kidney Day Office, Brussels, Belgium; ' Tanker Foundation, Chennai, India; 9 Division of Nephrology and Hypertension, 1st Department of Internal Medicine, AHEPA Hospital, Aristotle University of

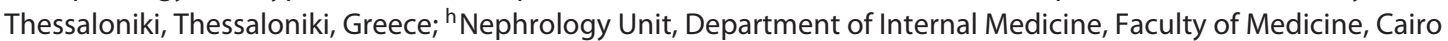
University, Giza, Egypt; 'Renal Unit, Department of Medicine, College of Medicine, University of Nigeria, Ituku-Ozalla, Nigeria; 'Division of Nephrology and Hypertension and Kidney Transplantation, University of California Irvine School of Medicine, Orange, CA, USA
\end{abstract}

\section{Keywords}

Kidney diseases $\cdot$ Prevention · Detection · Awareness

\begin{abstract}
The global burden of chronic kidney disease (CKD) is rapidly increasing with a projection of becoming the 5th most common cause of years of life lost globally by 2040. Aggravat-
\end{abstract}

This article was originally published in Kidney International, volume 97, pages 226-232, Copyright World Kidney Day Steering Committee (2020), and reprinted concurrently in several journals. The articles cover identical concepts and wording, but vary in minor stylistic and spelling changes, detail, and length of manuscript in keeping with each journal's style. Any of these versions may be used in citing this article.

$\begin{aligned} & \text { karger@karger.com } \\ & \text { www.karger.com/nef }\end{aligned}$
Karger

ingly, CKD is a major cause of catastrophic health expenditure. The costs of dialysis and transplantation consume up to $3 \%$ of the annual healthcare budget in high-income countries. Crucially, however, the onset and progression of CKD is often preventable. In 2020, the World Kidney Day campaign highlights the importance of preventive interventions - be it primary, secondary or tertiary. This complementing article focuses on outlining and analyzing measures that can be implemented in every country to promote and advance CKD

Philip Kam-Tao Li, MD, FRCP, FACP

Department of Medicine and Therapeutics

Prince of Wales Hospital, Chinese University of Hong Kong

30-32 Ngan Shing Street, Shatin, New Territories, Hong Kong (China) philipli@cuhk.edu.hk

Kamyar Kalantar-Zadeh, MD, MPH, PhD

Division of Nephrology, Hypertension and Kidney Transplantation

University of California Irvine School of Medicine

Orange, CA 92868 (USA)

kkz@uci.edu 
prevention. Primary prevention of kidney disease should focus on the modification of risk factors and addressing structural abnormalities of the kidney and urinary tracts, as well as exposure to environmental risk factors and nephrotoxins. In persons with pre-existing kidney disease, secondary prevention, including blood pressure optimization and glycemic control, should be the main goal of education and clinical interventions. In patients with advanced CKD, management of co-morbidities such as uremia and cardiovascular disease is a highly recommended preventative intervention to avoid or delay dialysis or kidney transplantation. Political efforts are needed to proliferate the preventive approach. While national policies and strategies for non-communicable diseases might be present in a country, specific policies directed toward education and awareness about CKD screening, management and treatment are often lacking. Hence, there is an urgent need to increase the awareness of the importance of preventive measures throughout populations, professionals and policy makers.

(c) 2020 World Kidney Day 2020 Steering Committee

\section{Introduction}

Around 850 million people currently are affected by different types of kidney disorders [1]. Up to one in ten adults worldwide has chronic kidney disease (CKD), which is invariably irreversible and mostly progressive. The global burden of CKD is increasing, and CKD is projected to become the 5th most common cause of years of life lost globally by 2040 [2]. If CKD remains uncontrolled and if the affected person survives the ravages of cardiovascular and other complications of the disease, CKD progresses to end-stage renal disease (ESRD), where life cannot be sustained without dialysis therapy or kidney transplantation. Hence, CKD is a major cause of catastrophic health expenditure [3]. The costs of dialysis and transplantation consume $2-3 \%$ of the annual health-care budget in high-income countries; spent on less than $0.03 \%$ of the total population of these countries [4].

Importantly, however, kidney disease can be prevented and progression to ESRD can be delayed with appropriate access to basic diagnostics and early treatment including life style modifications and nutritional interventions [4-8]. Despite this, access to effective and sustainable kidney care remains highly inequitable across the world, and kidney disease a low health priority in many countries. Kidney disease is crucially missing from the international agenda for global health. Notably absent from the impact indicators for the Sustainable Development
Goal (SDG) Goal 3. Target 3.4: By 2030 (By 2030, reduce by one third premature mortality from non-communicable diseases (NCDs) through prevention and treatment and promote mental health and well-being) and the latest iteration of the Untied Nation (UN) Political Declaration on NCDs. Kidney diseases urgently need to be given political attention, priority and consideration [9]. CKD is a major risk factor for heart disease and cardiac death, as well as for infections such as tuberculosis, and is a major complication of other preventable and treatable conditions including diabetes, hypertension, HIV and hepatitis [4-7]. As the Sustainable Development Goals (SDG) and Universal Health Coverage (UHC) agendas progress and provide a platform for raising awareness of NCD health care and monitoring needs, targeted action on kidney disease prevention should become integral to the global policy response [1].

\section{Definition and Classification of CKD Prevention}

According to the expert definitions including the Center for Disease Control and Prevention [10], the term "prevention" refers to activities that are typically categorized by the following three definitions: (1) Primary Prevention, implies intervening before health effects occur in an effort to prevent the onset of illness or injury before the disease process begins (2) Secondary Prevention suggests preventive measures that lead to early diagnosis and prompt treatment of a disease to prevent more severe problems developing and includes screening to identify diseases in the earliest stages, and (3) Tertiary Prevention indicates managing disease after it is well established in order to control disease progression and the emergence of more severe complications, which is often by means of targeted measures such as pharmacotherapy, rehabilitation, and screening for and management of complications. These definitions have important bearing in the prevention and management of the chronic kidney disease (CKD), and accurate identification of risk factors that cause CKD or lead to faster progression to renal failure as shown in Figure 1 are relevant in health policy decisions and health education and awareness related to CKD [11].

\section{Primary Prevention of CKD}

Measures to achieve effective primary prevention should focus on the two leading risk factors for CKD including diabetes mellitus and hypertension. Other CKD risk factors include polycystic kidneys or other congenital or acquired structural anomalies of the kidney and uri- 


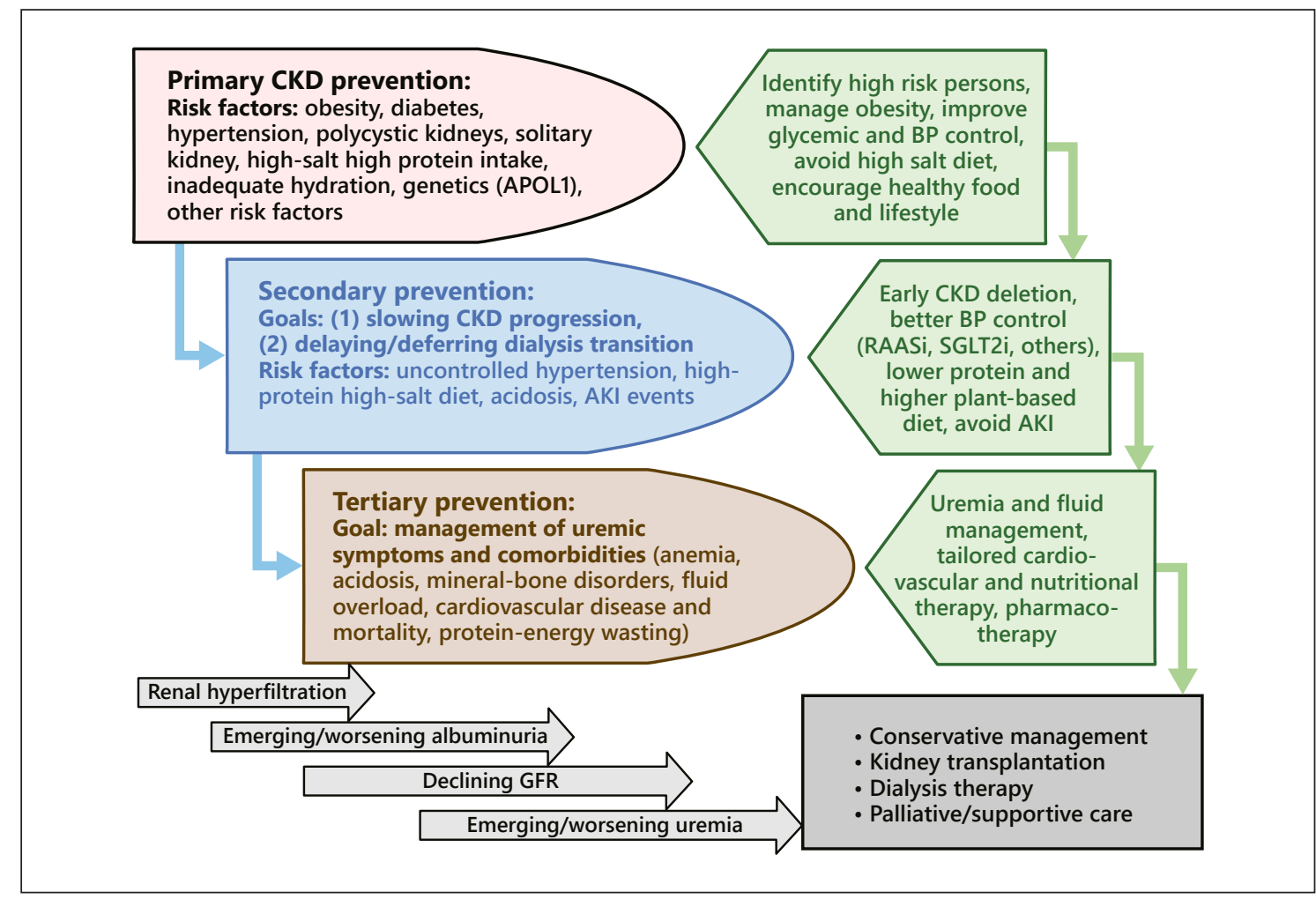

Fig. 1. Overview of the preventive measures in chronic kidney disease (CKD) to highlight the similarities and distinctions pertaining to primary, secondary, and tertiary preventive measures and their intended goals.

nary tracts, primary glomerulonephritis, exposure to nephrotoxic substances or medications (such as nonsteroidal anti-inflammatory drugs), having one single kidney, e.g. solitary kidney after cancer nephrectomy, high dietary salt intake, inadequate hydration with recurrent volume depletion, heat stress, exposure to pesticides and heavy metals (as has been speculated as the main cause of Mesoamerican Nephropathy), and possibly high protein intake in those at higher risk of CKD [8]. Among nonmodifiable risk factors are advancing age and genetic factors such as apolipoprotein 1 (APOL1) gene that is mostly encountered in those with sub-Saharan African ethnicity, especially among African Americans. Table 1 shows some of the risk factors of CKD.

Among measures to prevent emergence of de novo CKD are screening efforts to identify and manage persons at high risk of CKD, especially those with diabetes mellitus and hypertension. Hence, targeting primordial risk factors of these two conditions including metabolic syndrome and overnutrition is relevant to primary CKD prevention as is correcting obesity [12]. Promoting healthier lifestyle includes physical activity and healthier diet. The latter should be based on more plant-based foods with less meat, less sodium intake, more complex carbohydrates with higher fiber intake, and less saturated fat. In those with hypertension and diabetes, optimizing blood pressure and glycemic control has shown to be effective in preventing diabetic and hypertensive nephropathies. Persons with solitary kidney should avoid high protein intake above 1 gram per kilogram body weight per day $[13,14]$. Obesity should be avoided, and weight reduction strategies should be considered [12].

\section{Secondary Prevention in CKD}

Evidence suggests that among those with CKD, the vast majority have early-stage of the disease. i.e., CKD Stages 1 and 2 with microalbuminuria (30 to $300 \mathrm{mg} /$ day) or CKD Stage 3B (eGFR between 45 to $60 \mathrm{~mL} / \mathrm{min} / 1.73$ $\mathrm{m}^{2}$ ) [14]. For these earlier stages of CKD, the main goal of kidney health education and clinical interventions for "secondary prevention" is how to slow disease progression. Uncontrolled or poorly controlled hypertension is one of the most established risk factors for faster CKD progression. 
Table 1. Risk factors for de novo CKD and pre-existing CKD progression

\begin{tabular}{|c|c|c|}
\hline Risk Factor* & Contribution to de novo CKD & Contribution to CKD progression \\
\hline Diabetes mellitus & $\sim 50 \%$ of all CKDs & \\
\hline Hypertension & $\sim 25 \%$ of all CKDs & \\
\hline Obesity & $10-20 \%$ & \\
\hline Age & $\begin{array}{l}\text { Seen with advancing age, especially in the } \\
\text { setting of comorbid conditions }\end{array}$ & $\begin{array}{l}\text { Some suggests that older CKD patients may } \\
\text { have slower progression }\end{array}$ \\
\hline $\begin{array}{l}\text { Race, genetics and other hereditary factors: } \\
\text { - APOL1 gene } \\
\text { - Hereditary nephritis (Alport's) }\end{array}$ & $\begin{array}{l}\text { Common among those with African American } \\
\text { ancestors }\end{array}$ & \\
\hline $\begin{array}{l}\text { Acute glomerulonephritis: } \\
\text { post-infectious GN } \\
\text { Rapidly progressive GN }\end{array}$ & $<10 \%$ & Recurrent GN or exacerbation of proteinuria \\
\hline Polycystic kidney disorders & $<10 \%$, family history of cystic kidney disorders & \\
\hline $\begin{array}{l}\text { Acute kidney injury (AKI) } \\
\text { - Acute tubular necrosis (ATN) } \\
\text { - Acute interstitial nephritis (AIN) }\end{array}$ & Repeated AKI bouts can cause CKD & $\begin{array}{l}\text { Repeated AKI bouts can accelerate CKD } \\
\text { progression }\end{array}$ \\
\hline \multicolumn{3}{|l|}{$\begin{array}{l}\text { Autoimmune disorders } \\
\text { - Lupus erythematosus } \\
\text { - Other connective tissue disorders }\end{array}$} \\
\hline $\begin{array}{l}\text { Pharmacologic: } \\
\text { - Medications causing interstitial nephritides (NSAIDS, } \\
\text { CNI, chemotherapy, PPI, etc.) or ATN (aminoglycosides) } \\
\text { - Herbs and herbal medication }\end{array}$ & $\begin{array}{l}\text { Variable, e.g., in Taiwan, Chinese herb } \\
\text { nephropathy may be an important contributor }\end{array}$ & \\
\hline $\begin{array}{l}\text { Environmental: } \\
\text { heavy metal exposure }\end{array}$ & Rare & \\
\hline \multicolumn{3}{|l|}{$\begin{array}{l}\text { Acquired or congenital solitary kidney } \\
\text { - Cancer, donor or traumatic nephrectomy } \\
\text { - Congenital solitary kidney, unilateral atrophic kidney }\end{array}$} \\
\hline $\begin{array}{l}\text { Acquired urinary tract disorders and obstructive } \\
\text { nephropathy }\end{array}$ & $\begin{array}{l}\text { BPH in men } \\
\text { Gynecological cancers in women }\end{array}$ & \\
\hline Congenital anomalies of the kidney and urinary tract & Mostly in children and young adults & \\
\hline $\begin{array}{l}\text { Inadequate fluid intake } \\
\text { - Mesoamerican nephropathy } \\
\text { - Others }\end{array}$ & $\begin{array}{l}\text { Unknown risk, but high prevalence is } \\
\text { suspected in central America }\end{array}$ & $\begin{array}{l}\text { Whereas in earlier CKD stages adequate } \\
\text { hydration is important to avoid pre-renal AKI } \\
\text { bouts, higher fluid intake in more advanced } \\
\text { CKD may increase the risk of hyponatremia }\end{array}$ \\
\hline High protein intake & $\begin{array}{l}\text { Unknown risk, recent data suggest higher } \\
\text { CKD risk or faster CKD progression with high } \\
\text { protein diet, in particular from animal sources }\end{array}$ & $\begin{array}{l}\text { Higher protein intake can accelerate the rate } \\
\text { of CKD progression }\end{array}$ \\
\hline Cardiovascular diseases (cardiorenal) & Ischemic nephropathy & \\
\hline Liver disease (hepatorenal) & NASH cirrhosis, viral hepatitis & \\
\hline
\end{tabular}

* Many of these risk factors contribute to both de novo CKD and its faster progression and hence are relevant to both primary and secondary prevention.

The cornerstone of the pharmacotherapy in secondary prevention is the renin-angiotensin-aldosterone system inhibitors (RAASi). Low protein diet appears to have a synergistic effect on RAASi therapy [15]. Recent data sug- gest that a new class of anti-diabetic medications known as sodium-glucose cotransporter-2 Inhibitors (SGLT2i) can slow CKD progression, but this effect may not be related to glycemic modulation of the medication [16]. 
Whereas acute kidney injury (AKI) may or may not cause de novo CKD, AKI events that are superimposed on preexisting CKD may accelerate disease progression [17]. A relatively recent case of successful secondary prevention that highlights the significance of implementing preventive strategies in CKD is the use of a vasopressin V(2)receptor antagonists in Adult Polycystic Kidney Disease (ADPKD) [18].

\section{Tertiary Prevention in CKD}

In patients with advanced CKD, management of uremia and related comorbid conditions such as anemia, mineral and bone disorders, and cardiovascular disease is of high priority, so that these patients can continue to achieve highest longevity. Whereas many of these patients will eventually receive renal replacement therapy in form of dialysis therapy or kidney transplantation, a new trend is emerging to maintain them longer without dialysis by implementing conservative management of CKD.

\section{Approaches to Identification of Chronic Kidney Diseases}

The lack of awareness of CKD around the world is one of the reasons for late presentation of CKD in both developed and developing economies [19-21]. The overall $\mathrm{CKD}$ awareness among general population and even high cardiovascular risk groups across 12 low-income and middle-income countries was less than 10\% [21].

Given its asymptomatic nature, screening of CKD plays an important role in early detection. Consensus and Positional Statements have been published by International Society of Nephrology [22], National kidney Foundation [23], Kidney Disease Improving Global Outcomes [24], NICE Guidelines [25] and Asian Forum for CKD Initiatives [26]. There was lack of trials to evaluate screening and monitoring of CKD [27]. Currently most will promote a targeted screening approach to early detection of CKD. Some of the major groups at risk for targeted screening includes: Patients with diabetes, hypertension, those with family history of chronic kidney disease (CKD), individuals receiving potentially nephrotoxic drugs, herbs or substances or taking indigenous medicine, patients with past history of acute kidney injury and individuals older than 65 years $[26,28]$. CKD can be detected with 2 simple tests: a urine test for the detection of proteinuria and a blood test to estimate the glomerular filtration rate (GFR) $[23,26]$.
Given that currently a population screening for CKD is not recommended and it was claimed that it might add unintended harm to the general population being screened [27], there is no specialty society or preventive services group which recommends general screening [29]. Low-income to middle-income countries are illequipped to deal with the devastating consequences of $\mathrm{CKD}$, particularly the late stages of the disease. There are suggestions that screening should primarily include highrisk individuals, but also extend to those with suboptimal levels of risk, e.g., prediabetes and prehypertension [30].

\section{Cost-Effectiveness of Early Detection Programs}

Universal screening of the general population would be time-consuming, expensive and has been shown to be not cost-effective. Unless selectively directed towards high-risk groups, such as the case of $\mathrm{CKDu}$ in disadvantaged populations [31]. According to a cost-effectiveness analysis using a Markov decision analytic model, population-based dipstick screening for proteinuria has an unfavorable cost effectiveness ratio [32]. From an economic perspective, screening CKD by detection of proteinuria was shown to be cost-effective in patients with hypertension or diabetes in a systematic review [33]. CKD screening may be more cost-effective in populations with higher incidences of CKD, rapid rates of progression, and more effective drug therapy.

\section{A Rational Approach to CKD Early Detection}

The approach towards CKD early detection will include the decision for frequency of screening, who should perform the screening and intervention after screening [22] Screening frequency for targeted individuals should be yearly if no abnormality is detected on initial evaluation. This is in line with the Kidney Disease Improving Global Outcomes (KDIGO) resolution that the frequency of testing should be according to the target group to be tested and generally needs not be more frequent than once per year [24]. Who should perform the screening is always a question especially when the healthcare professional availability is a challenge in lower income economies. Physicians, nurses, paramedical staff and other trained healthcare professionals are eligible to do the screening tests. Intervention after screening is also important and patients detected to have CKD should be referred to primary care and general physicians with experience in management of kidney disease for follow up. A management protocol including referral to nephrologists should be provided to the primary care and general physicians $[21,24,26]$. 


\section{Integration of CKD Prevention into National NCD Programs}

Given the close links between CKD and other NCDs, it is critical that CKD advocacy efforts be aligned with existing initiatives concerning diabetes, hypertension, and cardiovascular disease, particularly in LMIC. Some countries and regions have successfully introduced CKD prevention strategies as part of their NCD programs. As an example, in 2003, a kidney health promotion program was introduced in Taiwan, with its key components including a ban on herbs containing aristolochic acid, public-awareness campaigns, patient education, funding for $\mathrm{CKD}$ research, and the setting up of teams to provide integrated care [34]. In Cuba, the Ministry of Public Health has implemented a national program for the prevention of CKD. The integration of CKD prevention into NCDs program, has resulted in the reduction of renal and cardiovascular risks in the general population. There has been an increased rate of the diagnosis of diabetes and of glycemic control, as well as an increased diagnosis of patients with hypertension, higher prescription use of renoprotective treatment with ACEI and higher rates of blood pressure control $[35,36]$. Recently, the US Department of Health and Human Services has introduced an ambitious program to reduce the number of Americans developing end-stage renal disease by 25 percent by 2030 . The program, known as the Advancing American Kidney Health Initiative, has set goals with metrics to measure its success; among them is to put more efforts to prevent, detect, and slow the progression of kidney disease, in part by addressing traditional risk factors like diabetes and hypertension. [37]. Ongoing programs, like the Special Diabetes Program for Indians (SDPI) represents an important part of this approach by providing team-based care and care management. Since its implementation, the incidence of diabetes-related kidney failure among American Native populations decreased by over 40 percent between 2000 and 2015 [38].

\section{The Interdisciplinary Prevention Approach}

Since 1994, a National Institute of Health consensus advocated for early medical intervention in predialysis patients. Owing to the complexity of care of CKD, it was recommended that patients should be referred to a multidisciplinary team consisting of nephrologist, dietitian, nurse, social worker, and health psychologist, with the aim to reduce predialysis and dialysis morbidity and mor-

Prevention of Kidney Diseases tality [39]. In Mexico, a nurse-led, protocol driven, multidisciplinary program reported better preservation in eGFR and a trend in the improvement of quality of care of CKD patients similar to those reported by other Multidisciplinary Clinic (MDC) programs in the developed world [40]. Future models should address region-specific causes of $\mathrm{CKD}$, increase the quality of diagnostic capabilities, establish referral pathways, and provide better assessments of clinical effectiveness and cost-effectiveness [41].

\section{Online Educational Programs for CKD Prevention and Treatment}

The e-Learning has also become an increasingly popular approach to medical education. Online learning programs for NCD prevention and treatment, including CKD, have been successfully implemented in Mexico. By 2015, over 5000 health professionals (including non-nephrologists) had been trained using an electronic health education platform [42]. It is equally important to promote "Prevention" with education programs for those at risk of kidney disease and with the general population at large. Education is key to engaging patients with kidney disease. It is the path to selfmanagement and patient-centered care. Narva found patient education is associated with better patient outcomes [43]. Obstacles include the complex nature of kidney disease information, low baseline awareness, limited health literacy, limited availability of CKD information, and lack of readiness to learn. Schatell found Web-based kidney education is helpful in supporting patient self-management [44]. Reputable healthcare organizations should facilitate users to have easier access to health information on their websites (see www. karger.com/doi/10.1159/000506528 online supplementary material, Appendix S1). Engagements of professional society, patient groups, charitable and philanthropic organizations promote community partnership and patient empowerment on prevention.

\section{Renewed Focus on Prevention and Awareness Raising and Education}

Given the pressing urgency pertaining to the need for increasing education and awareness on the importance of the preventive measures, we suggest the following goals to redirect the focus on plans and actions: 
1 Empowerment through health literacy in order to develop and support national campaigns that bring public awareness to prevention of kidney disease.

2 Population-based approaches to manage key known risks for kidney disease, such as blood pressure control and effective management of obesity and diabetes.

3 Implementation of the World Health Organization (WHO) 'Best Buys' approach including screening of at-risk populations for $\mathrm{CKD}$, universal access to essential diagnostics of early CKD, availability of affordable basic technologies and essential medicines and task shifting from doctors to front-line healthcare workers to more effectively target progression of CKD and other secondary preventative approaches.

"Kidney Health for Everyone, Everywhere" should be a policy imperative which can be successfully achieved if policy makers, nephrologists, healthcare professionals and the general public place prevention and primary care for kidney disease within the context of their Universal Health Coverage programs.

\section{Disclosure Statement}

All authors declare no competing interests.

\section{Appendix}

Members of the World Kidney Day Steering Committee are: Philip Kam-Tao Li, Guillermo Garcia-Garcia, Sharon Andreoli, Kamyar Kalantar-Zadeh, Latha Kumaraswami, Vassilios Liakopoulos, Siu-Fai Lui, Gamal Saadi, Luisa Strani, Ifeoma Ulasi.

\section{References}

1 International Society of Nephrology. (2019). 2019 United Nations High Level Meeting on UHC: Moving Together to Build Kidney Health worldwide. Retrieved 20 July 2019, https://www.theisn.org/images/Advocacy_4_pager_2019_Final_WEB_pagebypage. pdf

2 Foreman KJ, Marquez N, Dolgert A, Fukutaki K, Fullman N, McGaughey M, et al. Forecasting life expectancy, years of life lost, and allcause and cause-specific mortality for 250 causes of death: reference and alternative scenarios for 2016-40 for 195 countries and territories. Lancet. 2018 Nov;392(10159):205290.

3 Essue BM, Laba TL, Knaul F, et al. Economic burden of chronic ill health and injuries for households in low- and middle-income countries. In: Jamison DT, Gelband H, Horton S, et al., editors. Disease Control Priorities Improving Health and Reducing Poverty. 3rd ed. Washington (DC): World Bank; 2018. pp. $121-43$.

4 Vanholder R, Annemans L, Brown E, Gansevoort R, Gout-Zwart JJ, Lameire N, et al.; European Kidney Health Alliance. Reducing the costs of chronic kidney disease while delivering quality health care: a call to action. Nat Rev Nephrol. 2017 Jul;13(7):393409.

5 Luyckx VA, Tuttle KR, Garcia-Garcia G, et al. Reducing major risk factors for chronic kidney disease. Kidney Int Suppl. 2017;7(2):7187.

6 Luyckx VA, Tonelli M, Stanifer JW. The global burden of kidney disease and the sustainable development goals. Bull World Health Organ. 2018 Jun;96(6):414-422D.

7 Tonelli M, Muntner P, Lloyd A, Manns BJ, Klarenbach S, Pannu N, et al.; Alberta Kidney
Disease Network. Risk of coronary events in people with chronic kidney disease compared with those with diabetes: a population-level cohort study. Lancet. 2012 Sep;380(9844): $807-14$.

8 Kalantar-Zadeh K, Fouque D. Nutritional Management of Chronic Kidney Disease. N Engl J Med. 2017 Nov;377(18):1765-76.

9 United Nations General Assembly. Political declaration of the third high-level meeting of the General Assembly on the prevention and control of non-communicable diseases (2018) Retrieved from https://www.un.org/ ga/search/view_doc.asp?symbol=A/73/ L.2\&Lang $=\mathrm{E}$

10 Center for Disease Control and Prevention. "Picture of America" (www.cdc.gov/pictureofamerica). At a Glance - Executive Summary. 2017;2019.

11 Levey AS, Schoolwerth AC, Burrows NR, Williams DE, Stith KR, McClellan W; Centers for Disease Control and Prevention Expert Panel. Comprehensive public health strategies for preventing the development, progression, and complications of CKD: report of an expert panel convened by the Centers for Disease Control and Prevention. Am J Kidney Dis. 2009 Mar;53(3):522-35.

12 Kovesdy CP, Furth SL, Zoccali C, Tao Li PK, Garcia-Garcia G, Benghanem-Gharbi M, et al.; World Kidney Day Steering Committee. Electronic address: myriam@worldkidneyday.org; World Kidney Day Steering Committee. Obesity and Kidney Disease: Hidden Consequences of the Epidemic. J Ren Nutr. 2017 Mar;27(2):75-7.

13 Tantisattamo E, Dafoe DC, Reddy UG, Ichii $\mathrm{H}$, Rhee CM, Streja E, et al. Current Management of Patients With Acquired Solitary Kidney. Kidney Int Rep. 2019 Jul;4(9):1205-18.
14 Webster AC, Nagler EV, Morton RL, Masson P. Chronic Kidney Disease. Lancet. 2017 Mar; 389(10075):1238-52.

15 Koppe L, Fouque D. The Role for Protein Restriction in Addition to Renin-AngiotensinAldosterone System Inhibitors in the Management of CKD. Am J Kidney Dis. 2019 Feb; 73(2):248-57.

16 Mayer GJ, Wanner C, Weir MR, Inzucchi SE, Koitka-Weber A, Hantel S, et al. Analysis from the EMPA-REG OUTCOME ${ }^{\circledR}$ trial indicates empagliflozin may assist in preventing the progression of chronic kidney disease in patients with type 2 diabetes irrespective of medications that alter intrarenal hemodynamics. Kidney Int. 2019 Aug;96(2):489-504.

17 Rifkin DE, Coca SG, Kalantar-Zadeh K. Does AKI truly lead to CKD? J Am Soc Nephrol. 2012 Jun;23(6):979-84.

18 Torres VE, Chapman AB, Devuyst O, Gansevoort RT, Grantham JJ, Higashihara E, et al.; TEMPO 3:4 Trial Investigators. Tolvaptan in patients with autosomal dominant polycystic kidney disease. N Engl J Med. 2012 Dec; 367(25):2407-18.

19 Verhave JC, Troyanov S, Mongeau F, Fradette L, Bouchard J, Awadalla P, et al. Prevalence, awareness, and management of CKD and cardiovascular risk factors in publicly funded health care. Clin J Am Soc Nephrol. 2014 Apr; 9(4):713-9.

20 Chow KM, Szeto CC, Kwan B, Leung CB, Li PK. Public lacks knowledge on chronic kidney disease: telephone survey. Hong Kong Med J. 2014 Apr;20(2):139-44.

21 Ene-Iordache B, Perico N, Bikbov B, Carminati S, Remuzzi A, Perna A, et al. Chronic kidney disease and cardiovascular risk in six regions of the world (ISN-KDDC): a cross-sectional study. Lancet Glob Health. 2016 May;4(5):e307-19. 
22 Li PK, Weening JJ, Dirks J, et al. A report with consensus statements of the International Society of Nephrology 2004 Consensus Workshop on Prevention of Progression of Renal Disease. Kidney Int Suppl. 2005 Apr;(94):S2-7.

23 Vassalotti JA, Stevens LA, Levey AS. Testing for chronic kidney disease: a position statement from the National Kidney Foundation. Am J Kidney Dis. 2007 Aug;50(2):169-80.

24 Levey AS, Atkins R, Coresh J, Cohen EP, Collins AJ, Eckardt KU, et al. Chronic kidney disease as a global public health problem: approaches and initiatives - a position statement from Kidney Disease Improving Global Outcomes. Kidney Int. 2007 Aug;72(3):24759.

25 Crowe E, Halpin D, Stevens P; Guideline Development Group. Early identification and management of chronic kidney disease: summary of NICE guidance. BMJ. 2008 Sep 29; 337:a1530.

26 Li PK, Chow KM, Matsuo S, Yang CW, Jha V, Becker G, et al. Asian Chronic Kidney Disease (CKD) Best Practice Recommendations - Positional Statements for Early Detection of CKD from Asian Forum for CKD Initiatives (AFCKDI). Nephrology (Carlton). 2011; 16(7):633-41.

27 Fink HA, Ishani A, Taylor BC, Greer NL, MacDonald R, Rossini D, et al. Screening for, monitoring, and treatment of chronic kidney disease stages 1 to 3 : a systematic review for the U.S. Preventive Services Task Force and for an American College of Physicians Clinical Practice Guideline. Ann Intern Med. 2012 Apr;156(8):570-81.

28 Li PK, Ng JK, Cheng YL, Kwan TH, Leung CB, Lau MF, et al.; Hong Kong Society of Nephrology. Relatives in silent kidney disease screening (RISKS) study: A Chinese cohort study. Nephrology (Carlton). 2017 Dec;22 Suppl 4:35-42.
29 Samal L, Linder JA. The primary care perspective on routine urine dipstick screening to identify patients with albuminuria. Clin J Am Soc Nephrol. 2013 Jan;8(1):131-5.

30 George C, Mogueo A, Okpechi I, EchouffoTcheugui JB, Kengne AP. Chronic kidney disease in low-income to middle-income countries: the case for increased screening. BM] Glob Health. 2017 May;2(2):e000256.

31 Gonzalez-Quiroz M, Nitsch D, Hamilton S, O'Callaghan Gordo C, Saran R, Glaser J, et al.; DEGREE Study Steering Committee. Rationale and population-based prospective cohort protocol for the disadvantaged populations at risk of decline in eGFR (CO-DEGREE). BMJ Open. 2019 Sep;9(9):e031169.

32 Boulware LE, Jaar BG, Tarver-Carr ME, Brancati FL, Powe NR. Screening for proteinuria in US adults: a cost-effectiveness analysis. JAMA. 2003 Dec;290(23):3101-14.

33 Komenda P, Ferguson TW, Macdonald K, Rigatto C, Koolage C, Sood MM, et al. Costeffectiveness of primary screening for CKD: a systematic review. Am J Kidney Dis. 2014 May;63(5):789-97.

34 Hwang SJ, Tsai JC, Chen HC. Epidemiology, impact and preventive care of chronic kidney disease in Taiwan. Nephrology (Carlton). 2010 Jun;15 Suppl 2:3-9.

35 Almaguer M, Herrera R, Alfonso J, Magrans C, Mañalich R, Martínez A. Primary health care strategies for the prevention of end-stage renal disease in Cuba. Kidney Int Suppl. 2005 Aug;97(97):S4-10.

36 Alamaguer-Lopez M, Herrera-Valdez R, Diaz $\mathrm{J}$, Rodriguez $\mathrm{O}$. Integration of chronic kidney disease prevention into noncommunicable disease programs in Cuba. In: Garcia-Garcia G, Agodoa LY, Norris KC, editors. Chronic Kidney Disease in Disadvantaged Populations. London: Elsevier Inc.; 2017. pp. 357-65.
37 U.S. Department of Health and Human Services. Advancing American Kidney Health., 2019 accessed Sept 26, 2019 https://aspe.hhs. gov/pdf-report/advancing-american-kidneyhealth

38 U.S. Department of Health and Human Services. The Special Diabetes Program for Indians. Estimates of Medicare savings., 2019. Accessed Sept 26, 2019 https://aspe.hhs.gov/pdfreport/special-diabetes-program-indiansestimates-medicare-savings

39 Consensus Development Conference Panel. Morbidity and mortality of renal dialysis: an NIH consensus conference statement. Ann Intern Med. 1994 Jul;121(1):62-70.

40 Garcia-Garcia G, Martinez-Castellanos Y, Renoirte-Lopez K, Barajas-Murguia A, de la Torre-Campos L, Becerra-Muñoz LE, Gonzalez-Alvarez JA, Tonelli M. Multidisciplinary care for poor patients with chronic kidney disease in Mexico. Kidney Int Suppl (2011). 2013 May;3(2):178-83.

41 Stanifer JW, Von Isenburg M, Chertow GM, Anand S. Chronic kidney disease care models in low- and middle-income countries: a systematic review. BMJ Glob Health. 2018 Apr; 3(2):e000728.

42 Tapia-Conyer R, Gallardo-Rincon H, Betancourt-Cravioto M. Chronic kidney disease in disadvantaged populations: Online educational programs for NCD prevention and treatment. In: Garcia-Garcia G, Agodoa LY, Norris KC, editors. Chronic Kidney Disease in Disadvantaged Populations. London: Elsevier, Inc.; 2017. pp. 337-45.

43 Narva AS, Norton JM, Boulware LE. Educating Patients about CKD: The Path to SelfManagement and Patient-Centered Care. Clin J Am Soc Nephrol. 2016 Apr 7;11(4): 694-703.

44 Schatell D. Web-based kidney education: supporting patient self-management. Semin Dial. 2013 Mar-Apr;26(2):154-8. 